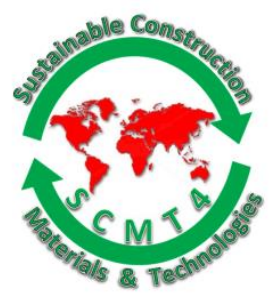

SCMT4

Las Vegas, USA, August 7-11, 2016

\title{
Remaining Capacity Assessment of Corrosion Damaged Column Bases
}

\author{
Bin Hu*1a, Ricky W.K ${ }^{1 b}$. Chan, and Chun-Qing Li ${ }^{1 \mathrm{c}}$ \\ ${ }^{1}$ School of Engineering, RMIT University, Australia. ${ }^{* 1 a}$ Email: $\langle s 3411763 @$ student.rmit.edu.au>,

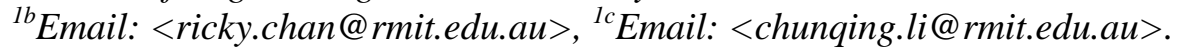

\begin{abstract}
Steel column base plates are integral parts in steel structures. They are widely used in foundations of various types of structures such as building frames, bridges, transmission towers, light poles and road signs. They spread column forces over a larger contact area and transfer forces to anchor bolts and cementitious grout beneath them. However, gradual thinning of base plates due to corrosion damage reduces their load bearing capacity and subsequently jeopardises the structural integrity of the entire structure. This paper presents a remaining capacity assessment method for steel column bases derived analytically based on a time-dependent corrosion rate model and the yield-line theory. Time dependent moment capacity of base plates is derived analytically as a function of time and geometric parameters of the plate. Solution to a wide-flange-section-to-column-base plate connection subjected to major axis bending moment is presented. Results of the analytical expression are compared to a three-dimensional nonlinear finite element model and good agreement is obtained. The proposed model may contribute to the prediction of remaining strength and repair schedule of corroded steel column bases.
\end{abstract}

\section{INTRODUCTION}

Column baseplate connections are commonly used as a structural foundation for various types of steel structures. Typically the steel baseplate is fillet welded to the bottom end of the column. Anchor bolts connect the base plate to a foundation concrete and a layer of grout is usually used to fill the gap [James M. Fisher, 2005]. Steel column bases are one of the most structurally critical components of the entire structure because its failure may result in a catastrophic collapse of a structure if the column bases no longer meet the safe structural criteria. They essentially support the gravity and lateral loads from the whole structure and transfer them to the ground. However, steel is vulnerable to corrosion, which gradually reduces the thickness of the material, and decreases structural strengths. For instance, a $4 \mathrm{~m}$ high steel light pole in Sydney, Australia toppled onto the footpath without any warning and it was later found rust and discolorations in the base of the pole. Fortunately, no injury was caused [Begley, 2015]. Therefore, it is necessary to develop a method to predict the remaining structural strength of steel column bases that are exposed in the corrosive environment.

For reinforced concrete structures, corrosion occurs in the embedded reinforcements and methods to evaluate and its time dependent structural deterioration model was developed [Li et al., 2005]. For steel structures, structural capacities (e.g. flexural, shear, bearing and lateral torsional bulking strength) of 
corroded I-beams were proposed [Sarveswaran et al., 1998, Rahgozar, 2009]. The remaining thickness of rusted I-beams is estimated in order to establish thickness reduction patterns of I-beam. Based on the damage pattern, the remaining structural capacities are predicted. However, most of the corrosion deterioration models were developed for structural members such as beams, very few studies was developed for column base connection.

This paper proposes a new analytical model to predict the corrosion-induced deteriorating moment capacity of steel column bases. The model is based on a power function deterioration mode of steel in conjunction with yield lines of base plates. To illustrate the concept, a base consists of a wide-flange column with a welded baseplate and two anchor bolts are presented. The anchor bolts are placed along the weak axis of the column and a layer of grout is applied between baseplate and concrete foundation. The new model is compared with a non-linear three-dimensional finite element model. For different exposure category, this time-dependent model may predict the strength steel column bases.

Yield Line Theory. Yield line theory was developed by Johansen [Johansen, 1962] and originally applied to the calculation of the collapse load or yield moment of reinforced concrete slabs. The theory can also be analogously employed to the plastic capacity prediction of steel plate and steel connections, which has been extensively applied [Zhao, 2003, Murray and Shoemaker, 2002, Tagawa and Gurel, 2005, Wheeler et al., 1998]. Yield line is a straight or curve line located at the plastically failed zone of the structural elements characterized by continuously formed plastic hinges. Most of the yield-line patterns are derived by the experimental observation. In addition, the plastic strain localisation derived from computer simulation is compared with the deformed specimen derived from experiment, and it was attested that the strain distribution from FE analysis is able to situate the yield lines [Wierzbicki and Huang, 1992].

Generally there are two methods to carry out yield line analysis, namely the equilibrium strip method and energy method (also called virtual work method) [Bhatt et al., 2014, Nilson et al., 2010]. The latter solution is a more popular and widely adopted, as it is relatively straightforward particular for more complex geometries. In principle, the external work done by the applied force or moment (equation 1) is equated to internal virtual work (equation 2) stored in the yield line.

$$
\mathrm{W}_{\mathrm{e}}=\mathrm{M}_{\mathrm{y}} \theta_{e} \text { or } \mathrm{W}_{\mathrm{e}}=\mathrm{F}_{\mathrm{f}} \Delta
$$

where $M_{y}$ is the yield moment of the structure and $\theta$ is the virtual rotation induced by the moment $M_{y} . F_{f}$ is the applied failure load in the structure and $\Delta$ is the arbitrary virtual deflection of the deformed structure.

$$
W_{i}=\int_{L_{n}} m_{p} \theta_{n} d s=\sum_{n=1}^{N} m_{p} \theta_{n} L_{n}
$$

where $\theta_{n}$ is the plastic rotation at the $n^{\text {th }}$ yield line, $L_{n}$ is the length of the $n^{\text {th }}$ yield line and $m_{p}$ is the plastic moment capacity per unit length of the structure as follows:

$$
m_{p}=\frac{f_{y} t_{p}^{2}}{4}
$$

Here $f_{y}$ is the yield stress of the material and $t_{p}$ is the plate thickness. At equilibrium, the flexural strength of the plate structure can be analytically expressed as

$$
M_{y}=\sum_{n=1}^{N} m_{p} \Theta_{n} L_{n} / \theta_{e}
$$


Corrosion rate. Corrosion rates of steel from various outdoor environments (i.e. rural, urban and marine environment) were extensively studied [Townsend and Zoccola, 1982, Albrecht and Naeemi, 1984]. A power function is derived from 8 years of atmospheric corrosion tests of weathering steel and carbon steel under different exposure environment, as described in equation 5.

$$
d(t)=A \cdot t^{B}
$$

where $d(t)$ is corrosion wastage depth (in $\mu \mathrm{m}$ ) after $t$ years of exposure time. $A$ is the initial corrosion loss at the unity time (i.e. the corrosion penetration after the first year of exposure). $B$ is the corrosion rate under the long-term exposure. Parameters $A$ and $B$ are typically determined by regression analysis of the measured data. Although other corrosion models are available, this power corrosion rate function is simple and thus most commonly used in literatures [Akgül and Frangopol, 2004, Townsend and Zoccola, 1982]. Suggested values of parameters $A$ and $B$ are given in Table 1. [Albrecht and Naeemi, 1984]

Table 1. Corrosion rate model parameters

\begin{tabular}{|c|c|c|c|c|}
\hline \multirow{2}{*}{ Environment } & \multicolumn{2}{|c|}{ Carbon Steel } & \multicolumn{2}{c|}{ Weathering Steel } \\
\cline { 2 - 5 } & $A$ & $B$ & $A$ & $B$ \\
\hline Rural & 34 & 0.65 & 33.3 & 0.5 \\
\hline Urban & 80.2 & 0.59 & 50.7 & 0.57 \\
\hline Marine & 70.6 & 0.79 & 40.2 & 0.56 \\
\hline
\end{tabular}

\section{FINITE ELEMENT ANALYSIS}

In order to verify the proposed yield line model (Equation 7) of steel column base, commercial finite element package ABAQUS 6.11 [ABAQUS, 2011] is adopted. Three dimensional continuum hexahedral brick elements with one reduced integration point (C3D8R) are used in the entire model.

\section{Geometry of the connection}

A typical column base configuration is selected for this study, as shown as figure 1 (a). Two anchor bolts are located along the neutral axis of column. This arrangement is typically assumed as pinned support, which is commonly used in lightly loaded portal frames and multistorey steel frames. An Australian 250UC column is fillet-welded onto a steel base plate $(300 \mathrm{mmx} 600 \mathrm{~mm} \times 32 \mathrm{~mm})$. Two $36 \mathrm{~mm}$ diameter anchor bolts are located along weak axis of the column with an embedded length of $1800 \mathrm{~mm}$. A $40 \mathrm{~mm}$ thick grout is filled between the baseplate and a $760 \mathrm{~mm}$ diameter cylindrical concrete foundation (3000 $\mathrm{mm}$ deep). For simplicity the soils around concrete base is not included. The surfaces of concrete foundation are restrained. The bolt holes in baseplate are $2 \mathrm{~mm}$ larger than the bolt shank diameter. In addition, due to symmetry of the geometry, only half of the structure is modelled to save computation effort (figure 1b).

\section{Material and contact properties}

Elastic-plastic material model is adopted for the steel of bolts, base plate and column. The Young's Modulus is 200GPa and Poisson's ratio is 0.3. The type of steel for base plate is assumed as 300 Plus steel with $300 \mathrm{MPa}$ yield stress, while the category of steel for the bolts is used as Grade 8.8 with 660MPa yield stress. On the other hand, the layer of grout is assumed as cement mortar. Concrete has a Young's Modulus of 26GPa and Poisson's ratio is 0.2. It is assumed the failure of the column base is happened because of the plastic bending of base plate and the concrete still remain elastic. 
The surface-to-surface contact is applied to the surface interaction of baseplate-bolts, baseplate-grout and grout-bolt. The friction coefficient is 0.3 for the tangential behaviour and hard contact is selected for the normal behaviour. Small sliding is selected for all contact interactions. The fillet welding between base plate and column bottom end is simulated by tie constraints. The bond behaviour between the bolts and concrete footing are assumed tied. The analysis is divided by three general static steps: (1) preloading the bolts; (2) fixing the bolt at certain length after the exertion of bolt load; (3) applying the displacement at the top end of the column.

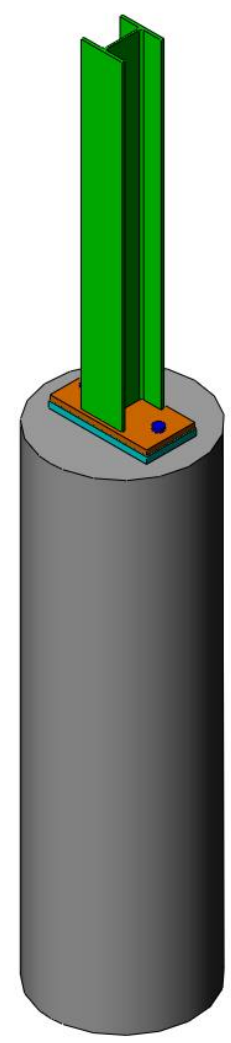

(a)

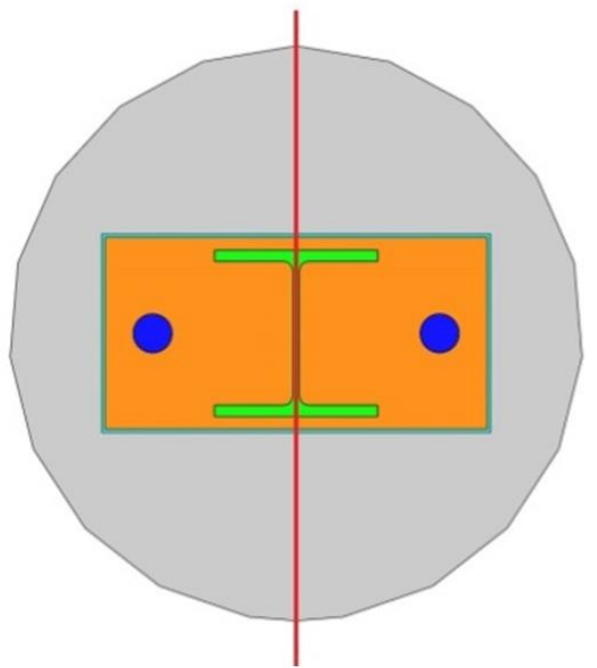

Plane of symmetry

Figure 1. (a) Overall geometry and (b) plane of symmetry

\section{PROPOSED TIME-DEPENDENT DETERIORATION MODEL FOR COLUMN BASES}

For bolted steel connections, failures usually occur at locations where yielding and excessive deformation occur. Stresses tend to concentrate around boltholes and yield lines due to prying action. figure 2 presents the assumed yield lines pattern on column baseplate upon bending with respect to column's strong axis. Dimensions required to define the yield lines are also annotated. Based on Equation 2, the virtual work is presented in Equation 6. Equating the external work and virtual internal work, the yield moment of the column base can be expressed as Equation 7.

$$
W_{i}=2 m_{p} \Delta\left[\frac{g}{a}+\frac{1}{a} \frac{b^{2}+c^{2}}{c}+2 \pi\left(\frac{a-d-b}{a}\right)+\frac{h\left(1-\frac{a-d}{a}\right)}{d}+j\left(\frac{1}{e}+\frac{1}{f}\right)\right]
$$




$$
M_{y}=2 a \frac{f_{y} T_{b p}^{2}}{4}\left[\frac{g}{a}+\frac{1}{a} \frac{b^{2}+c^{2}}{c}+2 \pi\left(\frac{a-d-b}{a}\right)+\frac{h\left(1-\frac{a-d}{a}\right)}{d}+j\left(\frac{1}{e}+\frac{1}{f}\right)\right]
$$

Geometric parameters (i.e. a,b,c,d,e,f,g,h,i,j) are determined by the yield line patterns and the values are summarised at Table 2. $\mathrm{f}_{\mathrm{y}}$ is the yield stress of the material and $\mathrm{T}_{\mathrm{bp}}$ is the original thickness of the baseplate

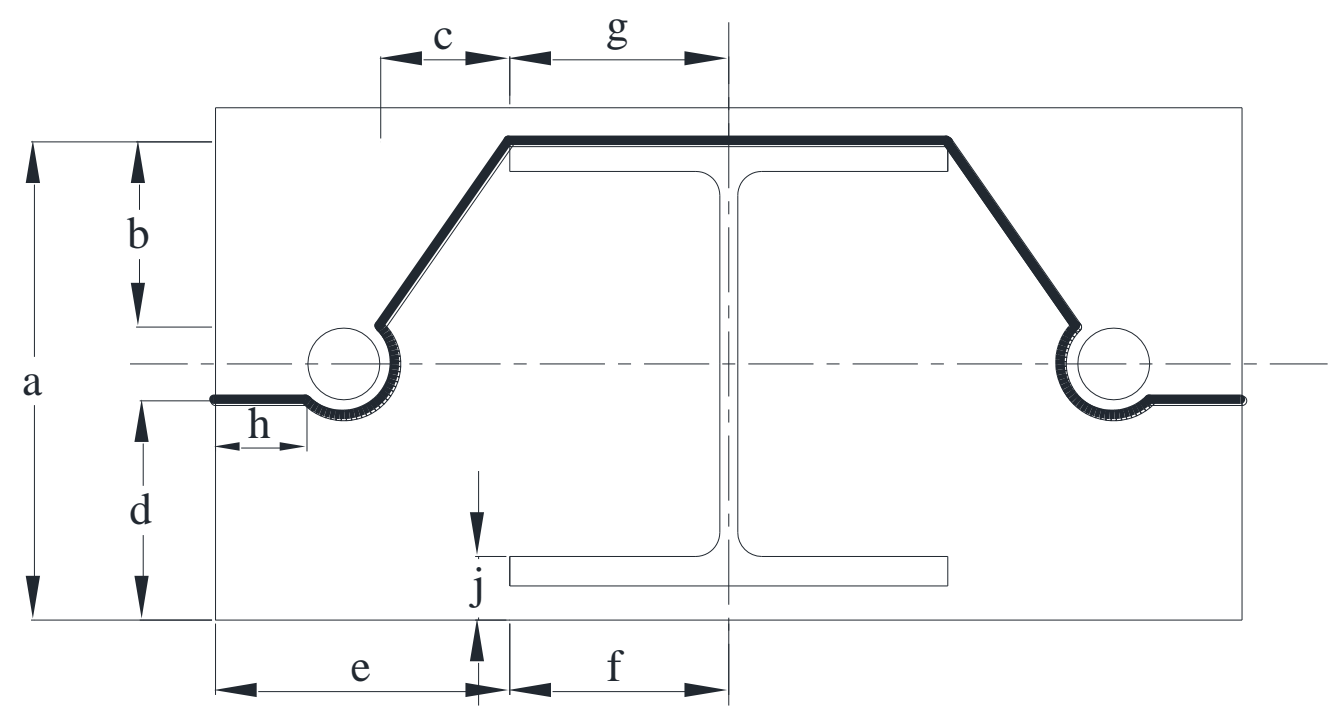

Figure 2. Yield line pattern on the base plate

\section{RESULTS AND DISCUSSION}

figure 3 shows the deformed shape and stress distribution of the column base. Under bending about column's strong axis, a portion of base plate is lifted from the base under prying action. It is clear that the base plate is spreading loads from column onto a large area. In figure 4, the strain distribution of deformed baseplate is shown. Strain is high in the bent areas of the plate and around vicinity of the bolt holes. The moment-rotation relationship obtained from FE analysis is shown in Fig 5, and the yield moment $(123.7 \mathrm{kNm})$ is determined by the intersection of the initial connection stiffness and post-yield stiffness. Also, the predicted yield moment $(126.6 \mathrm{kNm})$ derived from the analytical method is indicated in Fig 5. The parameters used are shown in Table 2. The comparison of the FE yield moment and predicted yield moment is summarised in Table 3. It is clear that a good agreement is obtained. Substituting Equation 5 into Equation 7, a time-dependent corrosion-induced deterioration model is derived:

$$
M_{y}(t)=2 a \frac{f_{y}\left(T_{b p}-A t^{B}\right)^{2}}{4} \times\left[\frac{g}{a}+\frac{1}{a} \frac{b^{2}+c^{2}}{c}+2 \pi\left(\frac{a-d-b}{a}\right)+\frac{h\left(1-\frac{a-d}{a}\right)}{d}+j\left(\frac{1}{e}+\frac{1}{f}\right)\right]
$$

\section{Table 2. Parameters in Equation 7}

\begin{tabular}{|c|c|c|c|c|c|c|c|c|c|c|c|}
\hline Parameters & $a$ & $b$ & $c$ & $d$ & $e$ & $f$ & $g$ & $h$ & $j$ & $f_{y}(\mathrm{MPa})$ & $T_{b p}$ \\
\hline Value $(\mathrm{mm})$ & 280 & 108.4 & 75.43 & 130 & 172 & 128 & 128 & 53.4 & 37.3 & 300 & 32 \\
\hline
\end{tabular}


Table 3. Comparison of FE and analytical results

\begin{tabular}{|c|c|c|}
\hline FE yield moment $(\mathrm{kNm})$ & $\begin{array}{c}\text { Predicted yield moment }- \text { Eq. 8 } \\
(\mathrm{kNm})\end{array}$ & Difference \\
\hline 123.7 & 126.6 & $2.4 \%$ \\
\hline
\end{tabular}

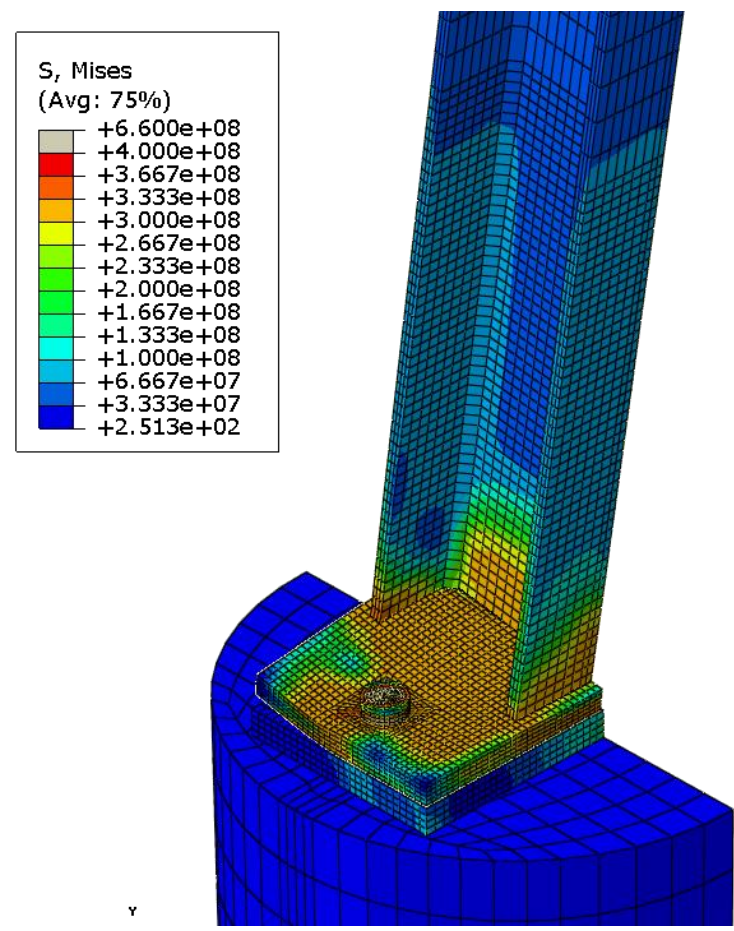

Figure 3. Stress distribution of deformed column base connection

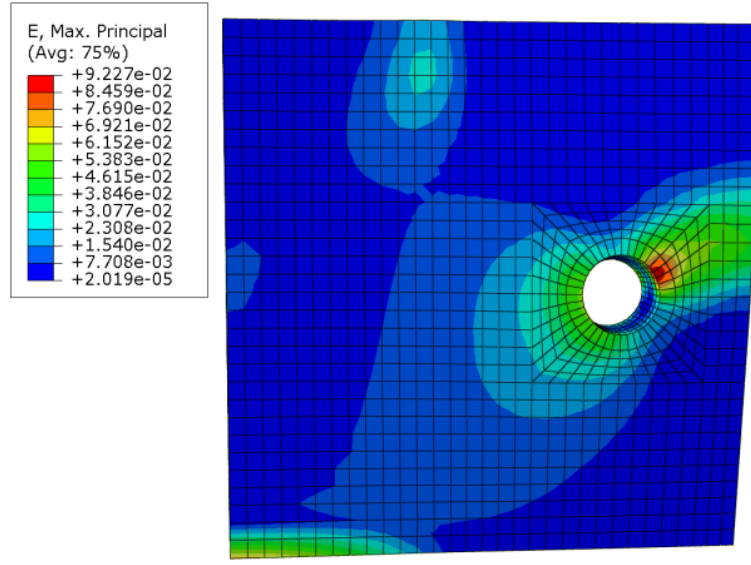

(a)
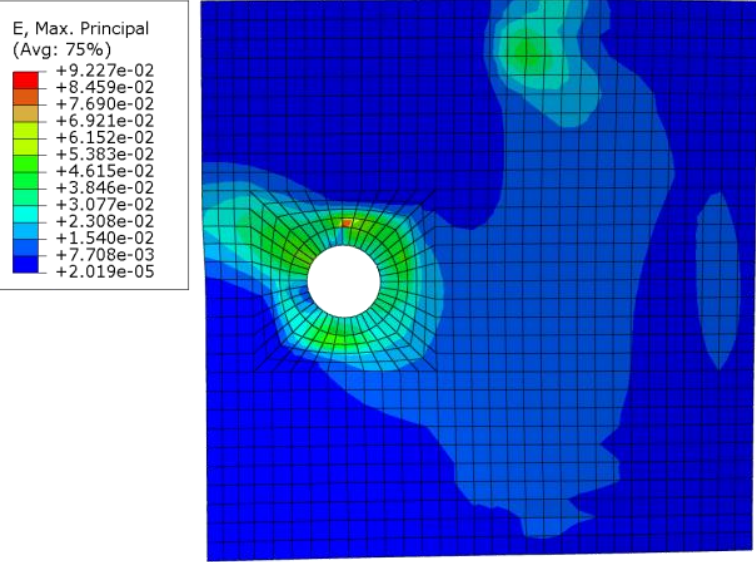

(b)

Figure 4. Strain distribution of baseplate (a) top view, (b) bottom view 


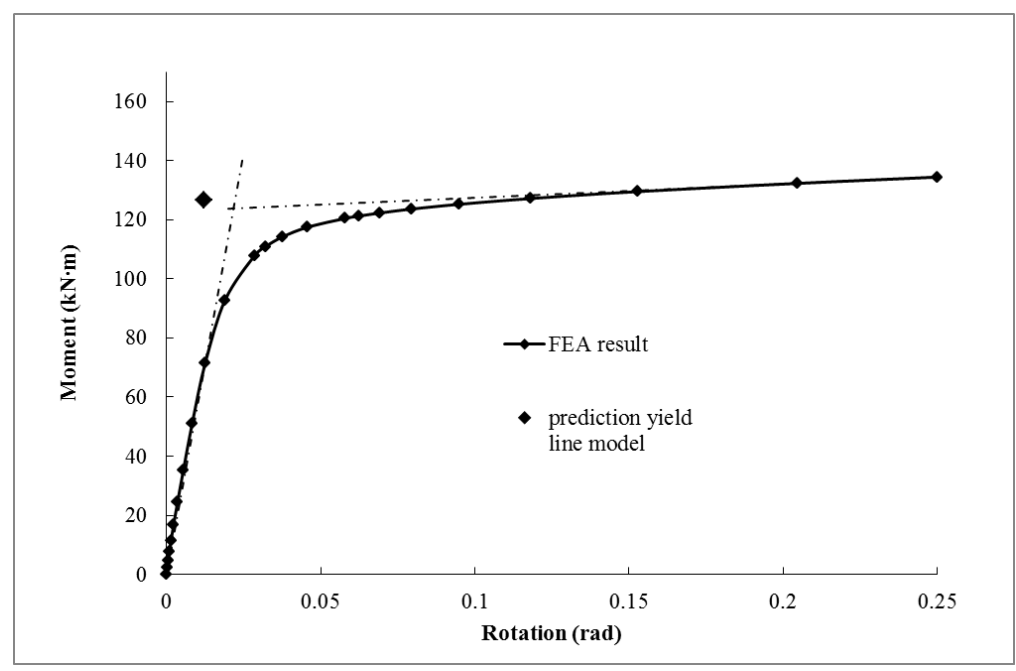

Figure 5. Moment-rotation relationship of the steel column base

Based on the parameters in Table 1, moment capacity of column bases under different exposure categories is predicted for the first 50 years, as shown in figure 6. It is assumed that no corrosion protection or maintenance is carried out during its service life. Normalised moment capacity to initial value is shown. It is clear that the deterioration the marine environment is the most corrosive while the rural is gentle. In 50 years, strong axis capacity reduces by approximately $10 \%$ under marine environment.

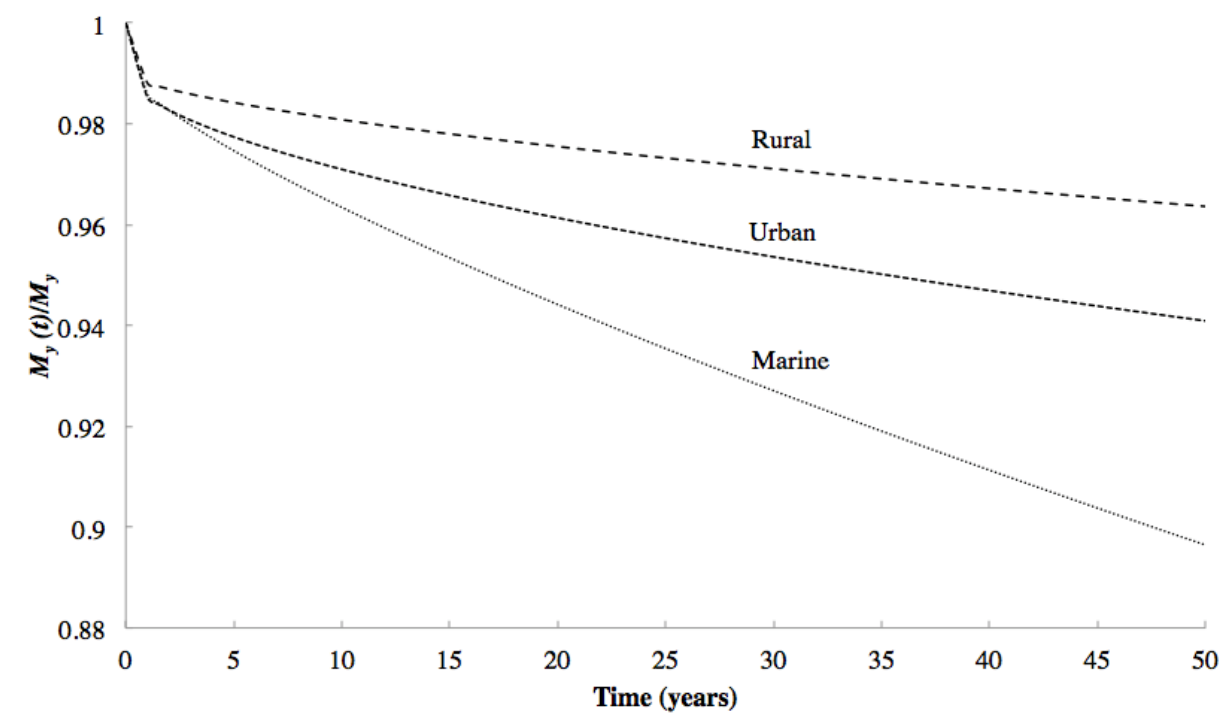

Figure 6. Prediction of deterioration of the column base

\section{CONCLUSION}

This paper proposes a new time-dependent corrosion-induced deterioration model, which is based on yield line theory and power corrosion rate model. Moment resistance of base plates is expressed analytically as a function of time. The yield line model is compared to a non-linear FE analysis and good agreement. The proposed model could be applied as a practical tool to predict the corrosion-induced 
failure time of the column bases. Using the proposed model, strength of column base plate over a period of 50 years and in three different exposure categories are presented.

A further study on the corroded structural steel members which originated from long-term natural exposure is being conducted to provide adequate statistical data. The further study is able to substantiate the newly proposed model.

\section{ACKNOWLEDGMENTS}

Financial support from Metro Trains Melbourne, Australia and Australian Research Council under DP140101547 and LP150100413 is gratefully acknowledged.

\section{REFERENCES}

ABAQUS 2011. ABAQUS/Standard, User's Manual I-III, version 6.11, Hibbit,Karlsson and Sorenson, Inc.

AKGÜL, F. \& FRANGOPOL, D. M. 2004. Lifetime performance analysis of existing steel girder bridge superstructures. Journal of Structural Engineering, 130(12), 1875-1888.

ALBRECHT, P. \& NAEEMI, A. H. 1984. Performance of weathering steel in bridges. NCHRP report, (272).

BEGLEY, P. 2015. Anzac Bridge light pole crashes over footpath. Sydney Morning Herald.

BHATT, P., MACGINLEY, T. J. \& CHOO, B. S. 2014. Reinforced Concrete Design to Eurocodes: Design Theory and Examples, Fourth Edition, Taylor \& Francis

JAMES M. FISHER, L. A. K. 2005. Design Guide 1: Base Plate and Anchor Rod Design,Second Edition American Institute of Steel Construction, Inc.

JOHANSEN, K. W. 1962. Yield-line theory, Cement and Concrete Association

LI, C., LAWANWISUT, W. \& ZHENG, J. 2005. Time-dependent reliability method to assess the serviceability of corrosion-affected concrete structures. Journal of structural engineering, 131(11), 1674-1680.

MURRAY, T. \& SHOEMAKER, L. 2002. Design Guide 16: Flush and Extended Multiple-Row Moment End-Plate Connections. American Institute of Steel Construction.

NILSON, A. H., DARWIN, D. \& DOLAN, C. W. 2010. Design of concrete structures, McGraw-Hill Higher Education

RAHGOZAR, R. 2009. Remaining capacity assessment of corrosion damaged beams using minimum curves. Journal of Constructional Steel Research, 65(2), 299-307.

SARVESWARAN, V., SMITH, J. \& BLOCKLEY, D. 1998. Reliability of corrosion-damaged steel structures using interval probability theory. Structural Safety, 20(3), 237-255.

TAGAWA, H. \& GUREL, S. 2005. Application of steel channels as stiffeners in bolted moment connections. Journal of Constructional Steel Research, 61(12), 1650-1671.

TOWNSEND, H. \& ZOCCOLA, J. 1982. Eight-year atmospheric corrosion performance of weathering steel in industrial, rural, and marine environments. Atmospheric Corrosion of Metals, ASTM STP, 76745-59. 
WHEELER, A., CLARKE, M., HANCOCK, G. \& MURRAY, T. 1998. Design model for bolted moment end plate connections joining rectangular hollow sections. Journal of Structural Engineering, 124(2), 164-173.

WIERZBICKI, T. \& HUANG, J. 1992. Initiation of plastic folding mechanism in crushed box columns. Thin-walled structures, 13(1), 115-143.

ZHAO, X. L. 2003. Yield line mechanism analysis of steel members and connections. Progress in Structural Engineering and Materials, 5(4), 252-262. 